\title{
Study of Mandibular Foramen in Adult Human Mandible Bones: An Osteological Study
}

\author{
Gupta $A K^{1}$, Shah $\mathrm{GJ}^{2}$, Prasad $\mathrm{RJ}^{3}$
}

\begin{abstract}
Introduction: The mandibular foramen is located on the medial surface of the ramus of mandible through which inferior alveolar nerve and vessels pass and supply the lower jaw. For dentists inferior alveolar nerve block is important to anesthetize the lower jaw for conducting various surgical procedures. Aims: To determine the accurate position of mandibular foramen through which inferior alveolar nerve and vessels were passing and supply the lower jaw and its clinical importance. Methods: This study was conducted on 35 dry mandible bones consisting of 70 mandibular foramens of unknown sex. All the important parameters were studied using vernier caliper. Results: The mean distance of mandibular foramen from mandibular notch was $21.00 \mathrm{~mm}$ on right side and $20.29 \mathrm{~mm}$ on left side, from posterior border was $12.63 \mathrm{~mm}$ on right side and $12.37 \mathrm{~mm}$ on left side, from angle of mandible was $20.60 \mathrm{~mm}$ on right side and $20.46 \mathrm{~mm}$ on left side, from base of the mandible was $23.57 \mathrm{~mm}$ on right side and 23.6 $\mathrm{mm}$ on left side, from anterior border was $16.74 \mathrm{~mm}$ on right side and $16.89 \mathrm{~mm}$ on left side. Conclusion: The accurate position of mandibular foramen varies. The knowledge of the average distance of mandibular foramen from various landmarks is useful for dental anesthesia and also helps to avoid complications.
\end{abstract}

Keywords: Inferior alveolar nerve, Local anesthesia, Mandible, Mandibular foramen

Authors:

1. Dr. Anil Kumar Gupta

2. Mr. Gaurav Jung Shah

3. Dr. Ram Jiban Prasad

${ }^{1}$ Department of Anatomy, Nepalgunj Medical College Chisapani, Banke

${ }^{2}$ Department of Community Medicine, Nepalgunj Medical College Chisapani, Banke

${ }^{3}$ Department of Anatomy, National Medical College, Birgunj

\section{Address for Correspondence:}

Dr. Anil Kumar Gupta

Department of Anatomy

Nepalgunj Medical College

Chisapani, Banke

Email: dr.anilkugupta@gmail.com

\section{INTRODUCTION}

The mandible forms the lower jaw and is the only movable bone of the skull. It is the largest and strongest bone of the face and consists of a horizontal horse-shoe shaped body and two broad and oblong rami projecting upward. ${ }^{1} \mathrm{~A}$ little above the center of the medial surface of the ramus is the mandibular faramen. ${ }^{2}$ The mandibular foramen leads into the mandibular canal, which runs downwards and forwards within the ramus, gently curving inferior within the body under the roots of the molar teeth. ${ }^{3}$ Just before entering the mandibular foramen and canal, inferior alveolar nerve gives off a small mylohyoid branch. In the mandibular canal, the inferior alveolar nerve runs downwards and forwards, generally below the apices of first and second premolars teeth. As well as the inferior alveolar artery runs posterior to the inferior alveolar nerve. ${ }^{3}$ The position of the mandibular foramen is an important anatomical landmark for effective anesthesia for inferior alveolar nerve in the field of dentistry procedures that includes dental extraction and placing mandibular implants. ${ }^{4}$ Aim of the study was to note the position of the mandibular foramen in adult human dry mandible bones and to highlight its clinical importance.

\section{METHODS}

A study of mandibular foramen was conducted on total 35 dry adult human mandible bones consisting of 70 mandibular foramens (35 right sides and 35 left sides) of unknown age and sex, from the collection in the Department of Anatomy, Nepalgunj Medical College, Chisapani, District Banke, Nepal. The study was conducted for the period of 5 months from October 2020 to February 2021. Deformed and damaged bones were excluded from the study. 

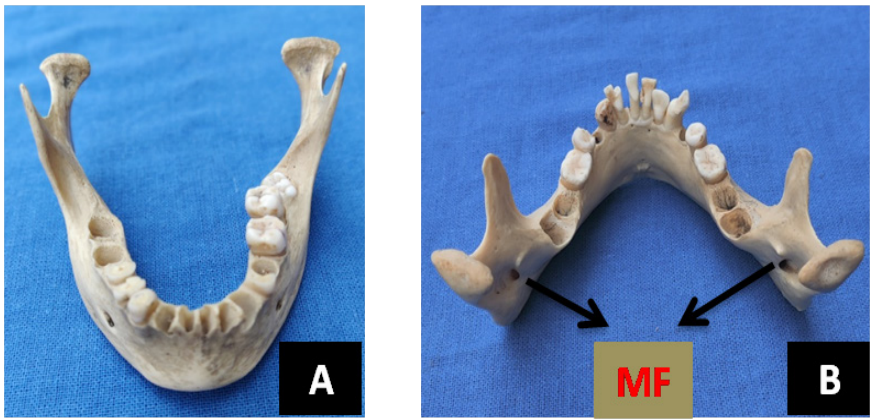

Figure 1: Mandible. (A) Anterior view (B) Posterior view showing mandibular foramina

The instruments used for the study were as follows and shown in Figure 1.

1) Vernier caliper: To measure distance of mandibular foramen from other bony landmarks.

2) Numbering stickers: The dry adult human mandible bones were numbered using the numbering sticker from 1 to 35 numbers in serial order.
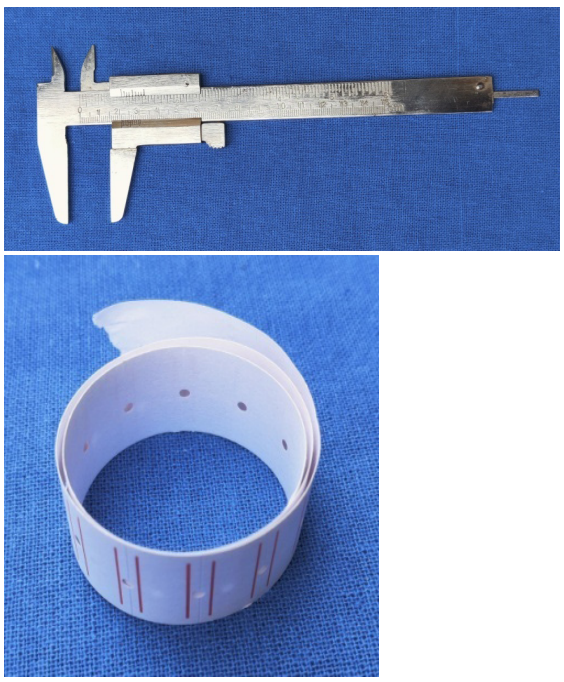

Figure 2: Instruments used in the present study

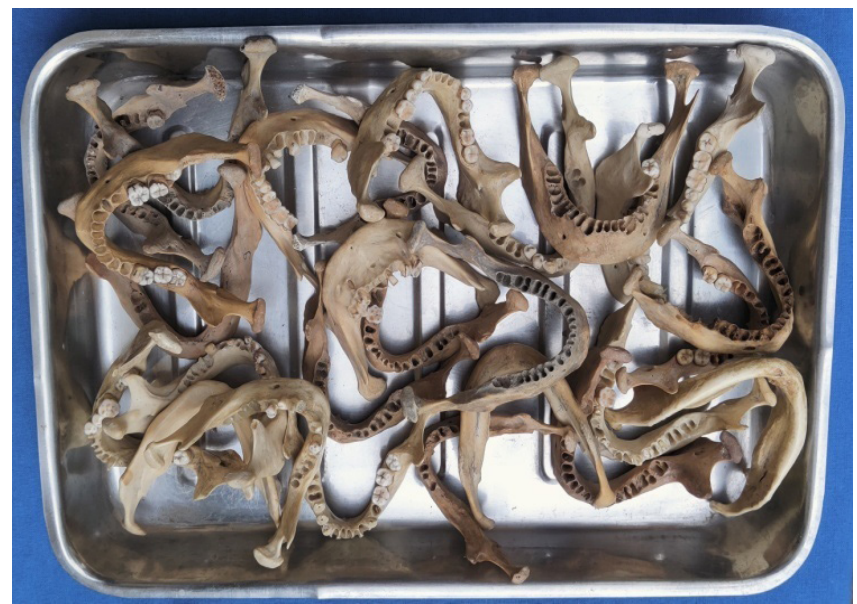

Figure3: Showing the bones used in the present study
Each mandible was numbered serially with numbering sticker to help in identification. The positions of the mandibular foramen from various landmarks were recorded on both the sides of ramus, with the help of vernier caliper of $0.1 \mathrm{~mm}$ accuracy.

\section{Following parameters were studied:}

1. $\mathbf{M F}=\mathbf{A}$ : - Superior border of mandibular foramen to the mandibular notch.

2. $\mathbf{M F}=\mathbf{B}$ : - Posterior border of mandibular foramen to the posterior border of ramus of mandible.

3. $\mathbf{M F}=\mathbf{C}$ : - Posterior - inferior border of mandibular foramen to the angle of mandible.

4. $\mathbf{M F}=\mathbf{D}$ : - Superior border of mandibular foramen to the base of the mandible.

5. $\mathbf{M F}=\mathbf{E}:-$ Anterior border of mandibular foramen to the anterior border of ramus of mandible. As shown in Figure 4 and 5.

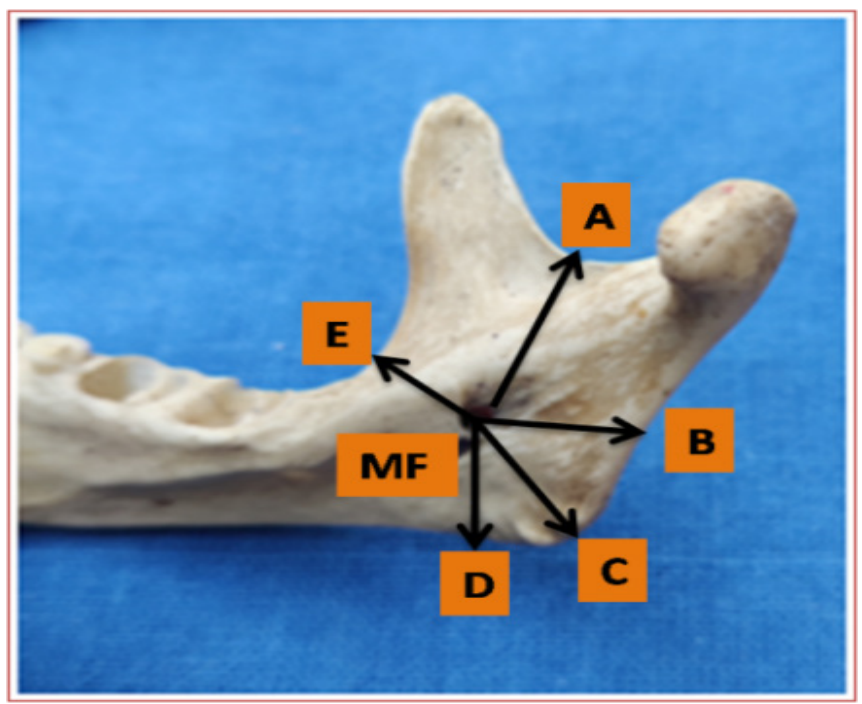

*MF= Mandibular foramen, $\mathrm{A}=$ Mandibular notch, $\mathrm{B}=$ Posterior border $\mathrm{C}=$ Angle of mandible $\mathrm{D}=$ Base of mandible, $\mathrm{E}=$ Anterior border

Figure 4: Showing various bony landmarks around the mandibular foramen

All the above parameter were carefully tabulated and analyzed.

The distance of various parameters from the mandibular foramen of mandible is measured and recorded. With the help of SPSS all the recorded measurements were calculated and find the Minimum, Maximum, Mean and Standard Deviation of all the parameters. 

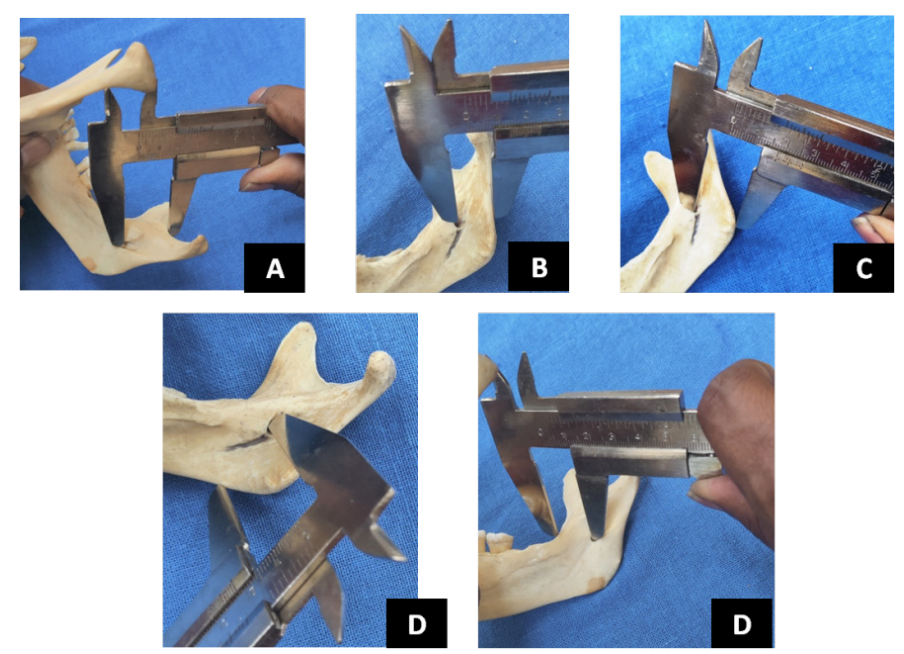

Figure 5: Measuring various dimensions with the help of vernier caliper

\section{RESULTS}

The measurement of various parameters of mandibular foramen on both sides (right and left) of mandible is shown in Table I.

The mean distance of right and left mandibular foramen from mandibular notch is $21.00 \mathrm{~mm}$ and $20.29 \mathrm{~mm}$ respectively. The mean distance of right and left mandibular foramen from posterior border of ramus is $12.63 \mathrm{~mm}$ and $12.37 \mathrm{~mm}$ respectively. The mean distance of right and left mandibular foramen from angle of ramus is $20.60 \mathrm{~mm}$ and $20.46 \mathrm{~mm}$ respectively. The mean distance of right and left mandibular foramen from base of mandible is $23.57 \mathrm{~mm}$ and $23.6 \mathrm{~mm}$ respectively. The mean distance of right and left mandibular foramen from anterior border of ramus is $16.74 \mathrm{~mm}$ and $16.89 \mathrm{~mm}$ respectively.

$\begin{array}{cccccc}\text { Measurement } & \text { N } & \text { Min } & \text { Max } & \text { Mean } & \text { Std. Deviation } \\ \text { Right MF- A } & 35 & 15 & 31 & 21.00 & 3.290 \\ \text { Left MF- A } & 35 & 15 & 30 & 20.29 & 3.322 \\ \text { Right MF- B } & 35 & 9 & 20 & 12.63 & 2.170 \\ \text { Left MF- B } & 35 & 9 & 21 & 12.37 & 2.365 \\ \text { Right MF- C } & 35 & 15 & 28 & 20.60 & 3.136 \\ \text { Left MF- C } & 35 & 12 & 27 & 20.46 & 3.467 \\ \text { Right MF- D } & 35 & 15 & 30 & 23.57 & 2.953 \\ \text { Left MF- D } & 35 & 12 & 30 & 23.06 & 3.621 \\ \text { Right MF- E } & 35 & 12 & 24 & 16.74 & 2.147 \\ \text { Left MF- E } & 35 & 9 & 26 & 16.89 & 2.908\end{array}$

Table I: Distance measured in $\mathrm{mm}$ between the mandibular foramen and their various parameters

\section{DISCUSSION}

Dentists commonly use inferior alveolar nerve when there is a need to anaesthetize the mandibular teeth. The injection of the anesthetic agent is given through an oral approach, by inserting the needle around the mandibular foramen, the opening into the mandibular canal on the medial aspect of the mandibular ramus, which gives passage to the inferior alveolar nerve and vessels. ${ }^{5}$ One of the most common reasons for the failure in the technique of inferior alveolar nerve block is due to the lack of the proximity between anesthetic needle and mandibular foramen and thus the inaccurate localization of the structures of the mandibular foramen. ${ }^{6}$ Greater variation is found in the position of mandibular foramen with different landmark. The variability of the position of mandibular foramen makes it difficult to anaesthetize the inferior alveolar nerve, variations may be due to different age, sex and difference in the methods used to measure the distance. ${ }^{7}$ The comparison for the location of mandibular foramen with previous authors is shown in tabulated form in Table II.

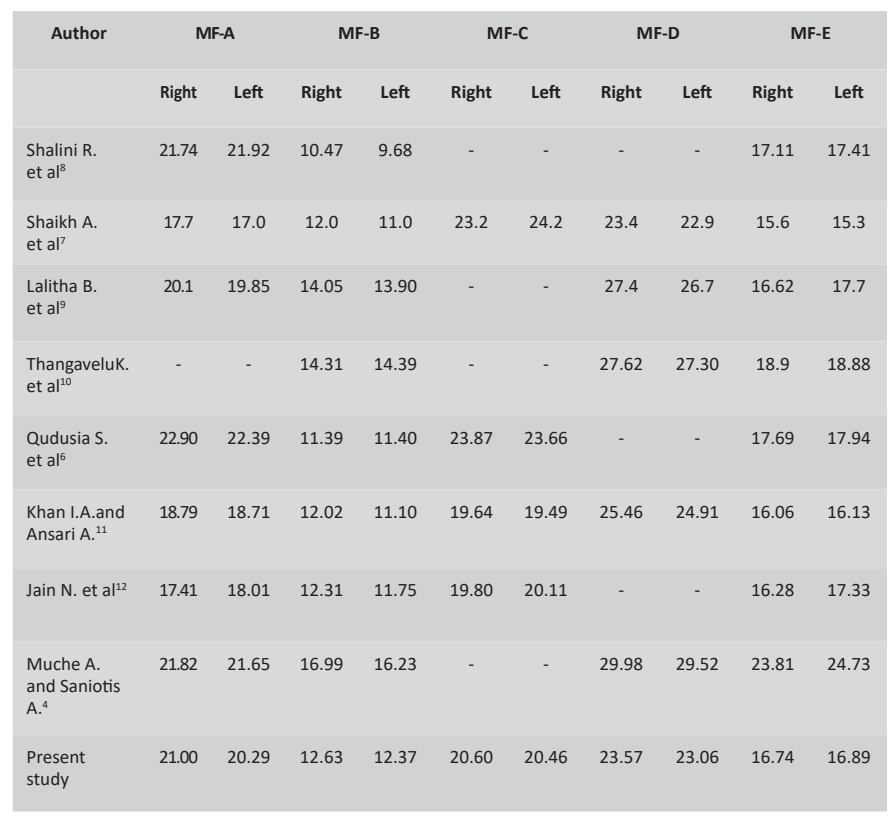

Table II: Comparison of mean result of the present study with previous results

The present study shows the distance from the MF to mandibular notch (A) was similar to Shalini R.et ${ }^{8}{ }^{8}$,Muche $A$. and Saniotis A. ${ }^{4}$, and Qudusia S.et al. ${ }^{6}$ However Shaikh A.et al ${ }^{7}$, Jain $\mathrm{N}$ et al ${ }^{12}$, Khan I.A. and Ansari A. ${ }^{11}$ reported lesser value. The distance from MF to posterior border (B) and anterior border (E) was almost similar in the present study when compared to other studies. The distance from MF to the base (D) was less in the present study when compared to other studies.

\section{LIMITATION}

Our study had small sample. However the study of large sample is required to give a conclusive opinion regarding the importance of this type of study in clinical practice.

\section{CONCLUSION}

The location of mandibular foramen varies and is very important to dental surgeons to be aware of it so as to anaesthetize the lower jaw for various dental surgeries with accuracy by giving 
inferior alveolar nerve block.

\section{REFERENCES}

1. Datta AK, editor. Human Anatomy, Head and Neck. $5^{\text {th }}$ ed. India: Current Book International; 2009.p. 40.

2. Seshayyan S, editor. Inderbir Singh's Text Book of Anatomy, Volume III. $6^{\text {th }}$ ed. India: Jypee Brothers Medical Publishers (P) Ltd; 2016.p.28.

3. Standring S, editor. Gray's Anatomy. $41^{\text {st }}$ ed. Elsevier; 2016.p.527.

4. Muche A, Saniotis A. Position of mandibular foramen and its clinical implication. Italian J of Anat and Embryology. 2019;124,n.3:319-28.

5. Singh DR, editor. Essentials of Anatomy for Dentistry Students. $1^{\text {st }}$ ed. India: Wolters Kluwer India Pvt Ltd; 2010.p.345.

6. Qudusia S, Shariff MH, Avadhani R. Study of surgical landmarks of mandibular foramen for inferior alveolar nerve block: An osteological study. Indian J of ClinAnat and Physio. 2016;3(1):37-40.

7. Shaikh A, Zuberi HR, Azhar AS. Study of mandibular foramen from different bony landmarks in dry human mandibles. IP Indian J of Anat and Surg of Head, Neck and Brain. 2018;4(2):40-43.

8. Shalini R, Varman CR, Veeramuthu M. Morphometric study on mandibular foramen and incidence of accessory mandibular foramen in mandibles of South Indian population and its clinical implications in inferior alveolar nerve block. Anat Cell Biol. 2016;49:241-48.

9. Lalitha B, Sridevi NS, Rao EKV. Morphometric analysis of mandibular foramen in dry adult human mandible. International J of Sci Study. 2016; 4(4):20-22.

10. Thangavelu K, Kannan R, Kumar NS, Rethish E, Sabitha S, Sayeeganesh N. Significance of localization of mandibular foramen in an inferior alveolar nerve block. J of Nat Sci, Bio and Med. 2012;4(2):156-60.

11. Khan IA, Ansari A. An anatomical study and clinical correlations of mandibular foramen in dry adult human mandibles of north Indian origin. Annals of International Med and Dent Research. 2016;2(4):161-64.

12. Jain N, Kazoka D, Jain S, Pilmane M. Anatomical variations in position of mandibular foramen: An East European morphometric study in dry adult human mandibles for achieving a successful inferior alveolar nerve block. Italian J of Anat and Embryology. 2019; 124, n.3: 392-402. 